Journal of Mechanical Engineering and Sciences

ISSN (Print): 2289-4659; e-ISSN: 2231-8380

Volume 12, Issue 4, pp. 4127-4140, December 2018

(C) Universiti Malaysia Pahang, Malaysia

DOI: https://doi.org/10.15282/jmes.12.4.2018.11.0357

\title{
Experimental investigations of friction stir welded AA6063 aluminum matrix composite
}

\author{
Narinder kaushik $^{1 *}$, Sandeep Singhal ${ }^{1}$, Rajesh $^{2}$, Pardeep Gahlot $^{2}$, B N Tripathi ${ }^{3}$ \\ ${ }^{1}$ Department of Mechanical Engineering \\ National Institute of Technology, Kurukshetra, Haryana - 136119, India \\ Phone: +91 7988850463 \\ *Email: narinderkaushik83@gmail.com \\ ${ }^{2}$ Department of Mechanical Engineering \\ UIET, MDU, Rohtak, Haryana-124001, India \\ ${ }^{3}$ Department of Mechanical Engineering \\ Lingayas Vidyapeeth, Faridabad, Haryana-121002, India
}

\begin{abstract}
The advancement of friction stir welding for joining of aluminum alloys and aluminum centered matrix composite has replaced the traditional welding techniques. In this experimental study, AA6063/10.5wt\%SiC composite has been produced by employing enhanced stir casting technique with the assistance of $\mathrm{Mg}$ metal powder. Specimen composite plates having thickness $6 \mathrm{~mm}$ were friction stir welded successfully. The impact of welding variables on mechanical and microstructural characteristics of weldments has been studied. The friction stir welding (FSW) was carried out at a rotation rate of tool of $1400 \mathrm{rpm}$ with a tool transverse rate of $124 \mathrm{~mm} / \mathrm{min}$. A cylindrical tool fabricated of high-speed steel (HSS) with square pin shape has been used for FSW. The results revealed that the ultimate tensile strength of the welded joint was $169 \mathrm{MPa}$, which was very close to the strength of the as-cast composite matrix. The microstructural study showed the reason for higher joint strength and microhardness. The welded butt joint exhibited a change in the microstructure at various four welding zones which transforms the mechanical characteristics of welded joints has been due to the asymmetrical flow of material and thermal cycles around the pin. The intense stirring action of the tool pin during FSW cracked the SiC particles in the weld nugget. In the weld region, a finegrained structure and homogeneous dispersion of $\mathrm{SiC}$ particles have been observed. The micro porosities associated with the base metal composite matrix were eliminated after FSW.
\end{abstract}

Keywords: Friction stir welding; Aluminum matrix composites; AA6063; microstructure; microhardness; ultimate tensile strength.

\section{INTRODUCTION}

Composite materials especially aluminum matrix composites (AMCs) have seized the consciousness of the materials world to a great degree. Aluminum matrix composites amalgamate the merits of monolithic Al-alloys and the unique advantages of ceramic materials [1]. The monolithic al-alloy reinforced with various types of reinforcement (SiC, TiC, B4C, Al2O3 etc) having different particle size has experienced excellent 
mechanical, wear and metallurgical properties as detailed by many researchers [1-4]. A sharp increase in the value of microhardness and minimum wear rate of AA6063 and AA6061 has been observed when reinforced with various wt\% and various sizes of SiC reinforcement particles respectively [5]. AMCs holds superb fatigue properties, excellent specific stiffness, lofty strength to weight even at elevated temperatures, excellent wear properties and high formability etc. [3-4]. AMCs have found a considerable attention in shipbuilding, automotive industries, aerospace sector, and architectural components because of those exceptional properties.

The joining of AMCs employing traditional fusion welding techniques depraved the joint characteristics because of consolidation instigated formation and chemical reactions [7]. The density difference inbetween ceramic particles and matrix phase evolved in the segregation of particles. The distribution of reinforcement agents in the nugget zone is very tough to keep as compared to that of the as-cast parent composite material. The upper viscosity of the matrix composite impedes the flow of material which prompts a heterogeneous dispersal of thermal stresses decreasing the strength of the joint. During the traditional fusion welding process, the amount of heat generated often commences reactions inbetween reinforcement phase and aluminum alloy matrix which generates brittle intermetallic amalgams in the nugget region. Welded joint produced by conventional fusion welding process are further tractable to porosity effect [8-11]. Hence it is recommended to employ solid-state joining techniques to weld al-matrix composites to remove these imperfections. Friction stir welding a solid-state welding technique (FSW) has been developed as an advanced joining technique to weld AMCs [12]. In FSW as the joint takes place in the solid state, therefore a consolidation instigated formation is not present in the nugget area. Hence, all the imperfections associated with fusion joining processes are vanished [13].

In recent years in literature, some investigations have been reported on friction stir welding of Al-matrix composites strengthened with different ceramic particles. [1423]. Chen et al. [14] has reported the microstructural examination of friction stir welded AA6063 reinforced with $(6,10.5$ vol.\%) B4C and showed a significant refinement of grains in the nugget zone of the matrix alloy. Vijay and Murugan [15] analyzed the impact of different tool pin profiles on microscopic examination of friction stir welded AA6061 reinforced with $10 \mathrm{wt} . \% \mathrm{TiB} 2$ and investigated that the square pin profile produced superior grain structure in the nugget zone which resulted in a higher tensile strength of the joint produced. Nami et al. [16] studied the influence of tool rotation speed on grain structure of FSWed AA6061 reinforced with $15 \mathrm{wt} . \% \mathrm{Mg}_{2} \mathrm{Si}$ and observed imperfections in the nugget area at high tool rotation rates. Gopalakrishnan and Murugan [17] optimized the UTS of FS welded AA6061 strengthened with (3-7 wt.\%) TiC particles by applying a mathematical optimization model. Guo et al. [18] used the EBSD process to observe the grain structure of friction stir fabricated joint of AA1100 reinforced with 16 vol.\% of B4C particles. Bozkurt et al. [19] studied the microstructural behavior of FS Welded al-alloy AA2124 reinforced with 25 vol.\% $\mathrm{SiC}$ and analyzed fissure of $\mathrm{SiC}$ reinforcement particles and sign of $\mathrm{SiO} 2$ phase in the nugget zone. Dinaharan and Murugan [20] examined the impact of FSW on the mechanical and microstructural behavior of Al-alloy AA6061 reinforced with (0-10 wt.\%) $\mathrm{ZrB}_{2}$ and studied that friction stir welding cracked the bunch of reinforcement particles in the as-cast composite into small fine grained particles of various sizes. Guo et al. [21] investigated shattering and smattering of reinforcement particles in FSW of Al-alloy AA1100 reinforced with 16 and 30 vol.\% B4C. Periyasamy et al. [22] examined the influence of heat generated on the mechanical and microstructural behavior of FS welded al-alloy AA6061 reinforced with 10 vol.\% 
SiC. Wang et al. [23] observed increased dispersion of $\mathrm{SiC}$ reinforcement particles in the nugget area of FS Welded AA2009 reinforced with 15 vol. \% SiC.

The aim of this research study is to investigate the influence of FSW on the microstructural and mechanical behavior of Al-alloy AA6063/10.5 wt. \% SiC AMC. The mechanical and metallurgical behavior of friction stir welded as-cast AA6063/10.5 wt. \% SiC AMC is differentiated with the fabricated al-alloy matrix and as-cast aluminum matrix composite to understand the influence of $\mathrm{SiC}$ particle and friction stir welding (FSW). The impact of FSW variables i.e., the rotation rate of the tool and traverse rate of the tool on shape, size, and scattering of $\mathrm{SiC}$ particles in the nugget zone is discussed. The refinement of grains following to FSW and the macrostructure distinctly identified the various four zones are also studied in this work.

\section{EXPERIMENTAL PROCEDURE}

Fabrication of AA6063/SiC Aluminum Matrix Composite and Friction Stir Welding AA6063 al-alloy strengthened with $\mathrm{SiC}$ particles has been used for producing aluminum matrix composite (AMC) in this present work. The matrix is a standard AA6063 aluminum alloy having the formal chemical composition as presented in Table 1. Silicon carbide ( $\mathrm{SiC}$ ) strengthened AA6063 matrix composite was manufactured by using stir casting technique in a top loading electric resistance muffle furnace as reported in the literature [24]. The average size of $\mathrm{SiC}$ particles was 400 mesh $(37 \mu \mathrm{m})$. Castings have been produced by reinforcing ( 0 and $10.5 \mathrm{wt} \%) \mathrm{SiC}$ particles. For friction stir welding slashed composite specimens of size (100 mm x $50 \mathrm{~mm}$ x $6 \mathrm{~mm}) \mathrm{mm}$ has been prepared, cleaned and then butt welded along the joint line. The welding experiments have been performed on an automated vertical milling machine by using the specially designed fixture as shown in Figure 2 to clamp the welding plates. The suitable fixture design with backing plates is the most essential component in FSW in order to block the lifting of the plates to be welded during the welding process and also to confirm consistent temperature distribution across the specimen plates [25]. Based on visual inspection the welding variables have been adjusted to produce defect-free welds. Welding experiments have been performed at a tool rotational speed of $1400 \mathrm{rpm}$ and tool transverse speed of $124 \mathrm{~mm} / \mathrm{min}$. For friction stir welding a tool made up of high-speed steel hardened up to $62 \mathrm{HRC}$ with a square pin shape as shown in Figure 1(a) has been used to produce highquality butt joints [26]. The manufactured tool with dimensions is shown in Figure 1(b). The view of successfully friction stir welded AMC plate is shown in Figure 3. The observed defected friction stir welded specimens has been rejected and also subjected to further mechanical and microstructural characterization. The defect-free welded plates were subjected to mechanical and microstructural analysis.

Table 1. Chemical composition of AA6063 Al-alloy.

\begin{tabular}{ccccccccccc}
\hline Element & $\mathbf{M g}$ & $\mathbf{S i}$ & $\mathbf{F e}$ & $\mathbf{C u}$ & $\mathbf{M n}$ & $\mathbf{Z n}$ & $\mathbf{C r}$ & $\mathbf{N i}$ & $\mathbf{T i}$ & Al \\
\hline Wt. \% & 0.96 & 0.45 & 0.35 & 0.10 & 0.10 & 0.10 & 0.09 & 0.02 & 0.01 & Remainder \\
\hline
\end{tabular}



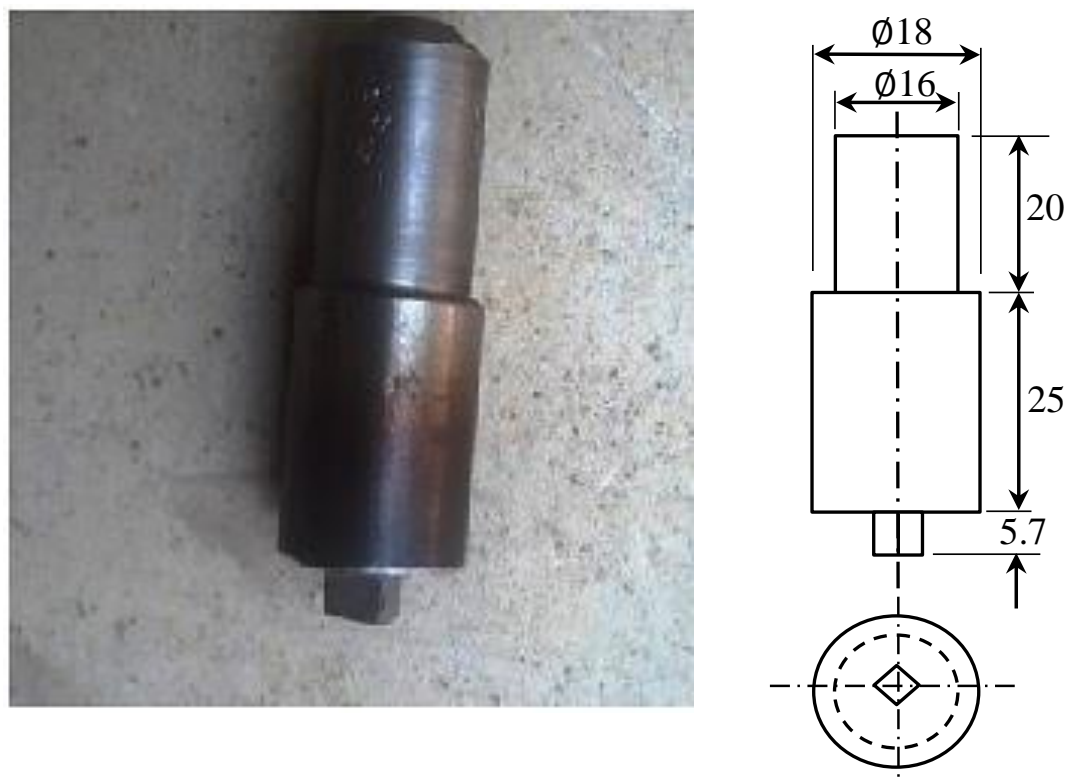

Figure 1. (a) FSW tool with a square pin profile and (b) Tool dimensions.

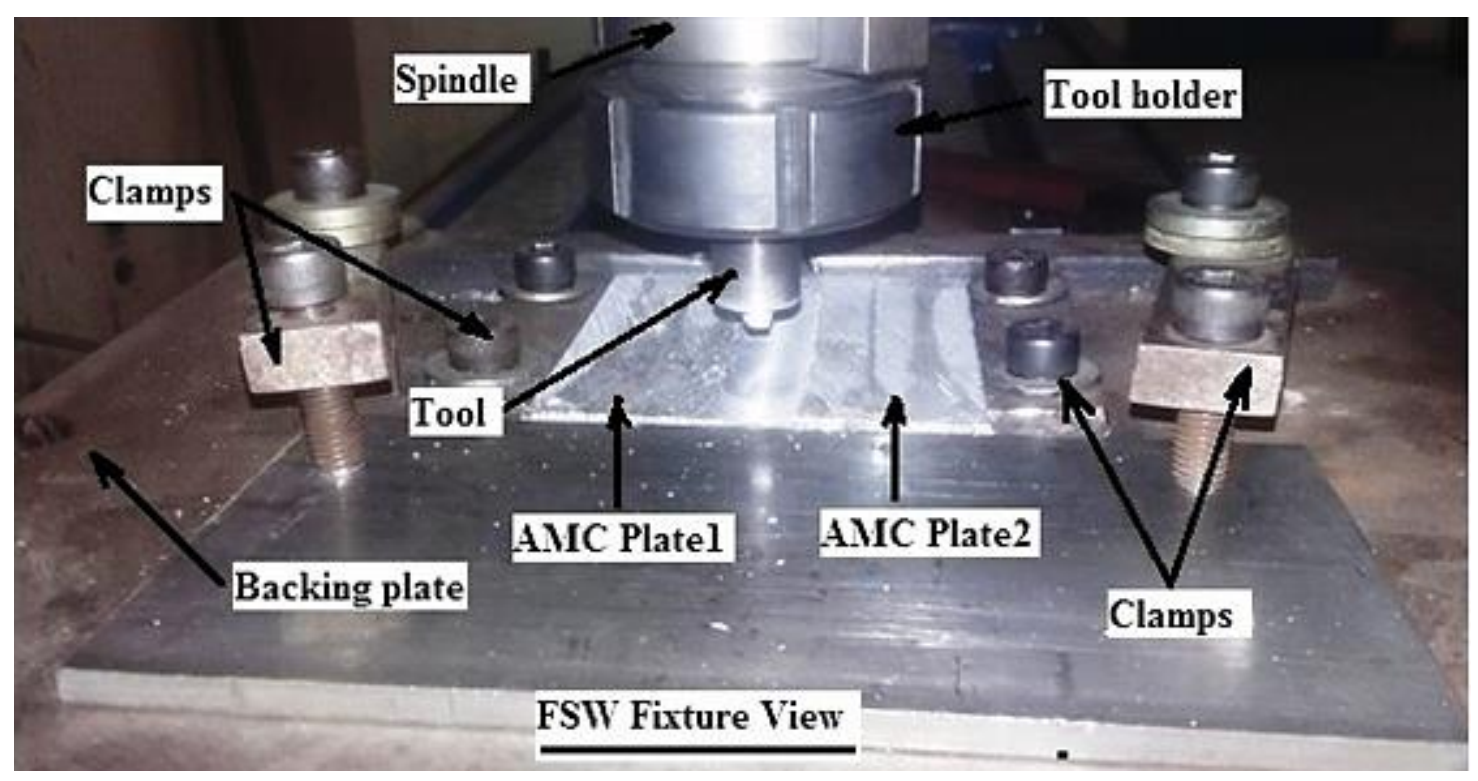

Figure 2. View of FSW fixture. 


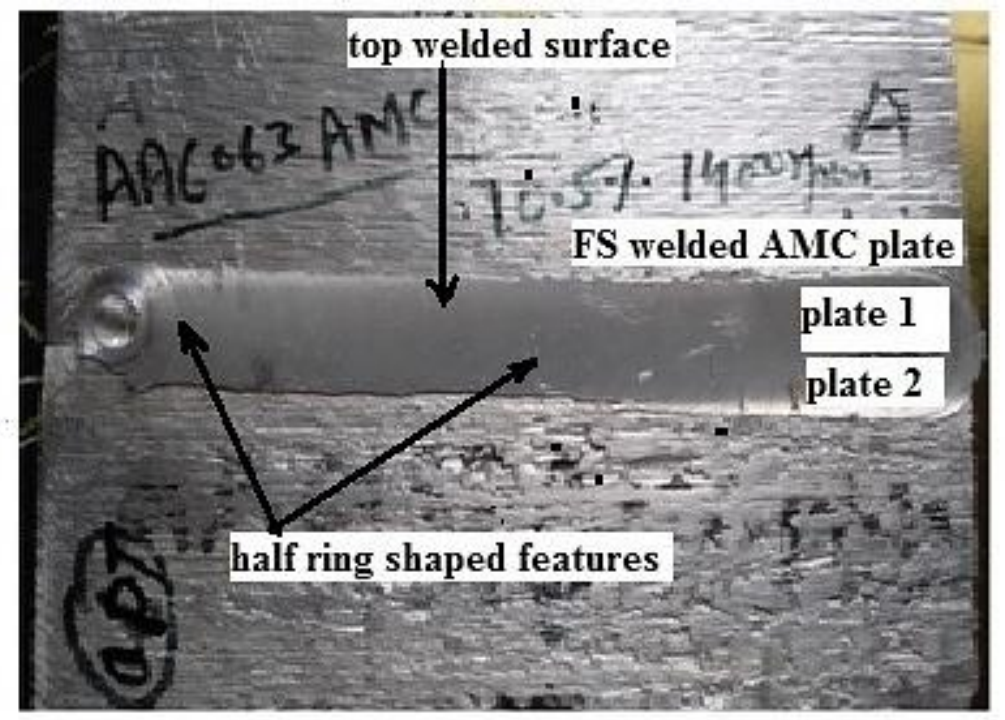

Figure 3. Friction stir welded AA6063/10.5\% SiC AMC plate.

\section{Material Characterization and Testing}

The metallographic specimens have been prepared from as-cast AA6063, as cast AA6063 AMC and as welded AA6063 AMC according to the standard metallographic procedure followed by mirror polishing and etching with Keller's reagent $(\mathrm{HCL}+\mathrm{HF}+\mathrm{HNO} 3+$ distilled water). The standard tensile specimen has been slashed perpendicular to the joint line and prepared according to ASTM E8-04 standard from all the samples [6]. The tensile specimens have been prepared with gauge length $60 \mathrm{~mm}$, gauge width $7 \mathrm{~mm}$, and thickness $6 \mathrm{~mm}$. The tensile tests have been performed on a universal tensile testing machine (UNITEK-94100) of maximum capacity upto $100 \mathrm{kN}$ supplied by blue star. The microstructure of the FS welded specimens has been analyzed using a scanning electron microscope (JSM-6100) and also an optical microscope made by Dewinter. Using SEM technology the distribution of reinforced SiC particles has been scanned and captured at 500x and examined in the whole cross-section of the FS welded specimen. The microstructural analysis of as-cast Al-matrix, as cast AMC and welded joint, has been also carried out in the same manner. The microhardness examination of the FS welded and other specimens (as cast matrix alloy and composite) has been performed using FIE model MV1-PC Vickers microhardness tester. The hardness measurements have been performed at various locations on both sides of the weld region at a constant load of .05kgf for a dwell time of 15 seconds. The hardness measurements have been then described as average microhardness.

\section{RESULTS AND DISCUSSION}

\section{Macroscopic and Microscopic Observation of the FS Welded Joint}

The top surface of the welded specimen has been characterized by half ring-shaped features as shown in Figure 3 just like those established during the milling operation. The firm pressure applied by the tool shoulder and traverse rate of the tool produces these type of half ring-shaped features on the top surface of the two welding plates. The visual examination of the top surface reveals a plane smooth surface and absence of any cracks, voids, indentation, and immoderate flares. 
In Figure 4 the macro-structural examination of friction stir welded AA6063/10.5 wt. \% SiC composite plate is depicted. The macro-structural study of the welded joint revealed the continual flow of plasticized material from the advancing side (AS) to retreating side (RS). No defects were observed in the macrograph for the welded joint [27]. The stir zone (SZ) in this study was observed with a basin structure as reported by others [27]. The different sections of the welded joint such as WZ (weld zone), HAZ (heat affected zone), TMAZ (thermomechanically affected zone) and BM (base metal) are clearly identified in the macrograph as shown in Figure 4 [28]. The WZ and TMAZ are characterized by adjoining regions. TMAZ is that region which experienced high thermal cycles and subjected to plastic deformation under the action of thermal cycles. WZ and TMAZ borderline have been characterized by the appearance of small-sized $\mathrm{SiC}$ reinforcing agents in the weld zone (WZ) produced due to the stirring tool action. Similar examinations have been investigated in the literature [14, 21, 29].

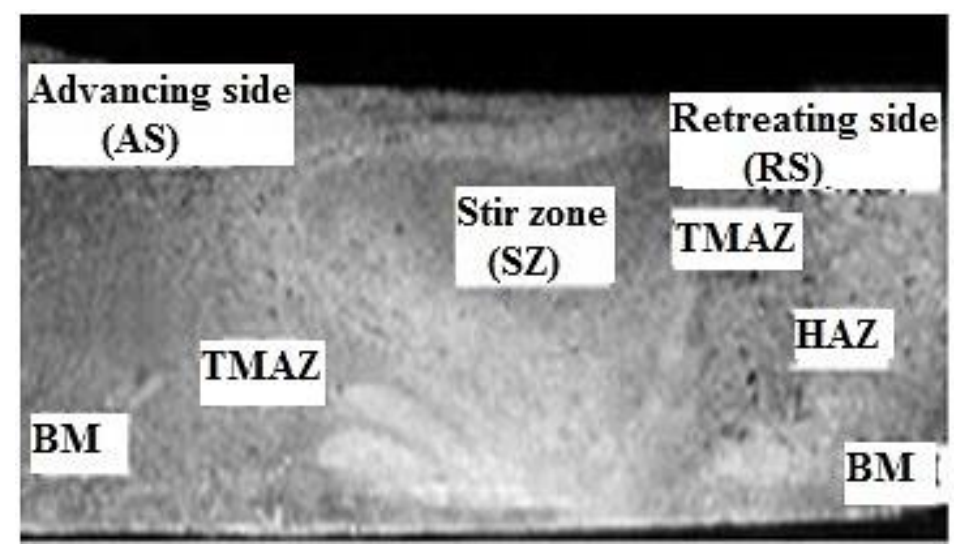

Figure 4. Macrostructure of FS welded AA6063/10.5\% SiC composite.

Figure 5 depicted the scanning electron microscope (SEM) pictures of as-cast AA6063, as-cast AA6063 al-matrix composite, and as-welded AA6063 AMC joint. The as-cast AA6063/10.5\% SiC matrix composite revealed the homogeneous distribution of SiC particles as shown in Figure 5(b) and 6(a). A little quantity of bunching of $\mathrm{SiC}$ agents in the cast composite matrix has been seen at some locations. A large number of small round shaped particles in the weld zone (WZ) has been observed which were not seen in the as-cast matrix composite. The existence of such fragmented particles in the weld zone occurred due to the stirring action of the rotating tool. The rotational effect of the tool causes wear of the $\mathrm{SiC}$ particles, advancing the partition of sharp edges $\mathrm{SiC}$ agents and resulting in small disc-shaped particles of both bigger size particles and scattered particles. A similar phenomenon has been observed in many FS welded aluminum matrix composites with different reinforcements [30-33]. The adequate stirring action of the tool creates grain refinement and rounded up of $\mathrm{SiC}$ particles in the $\mathrm{WZ}$ (weld zone). The equiaxed recrystallized grains following to FSW in the nugget zone smaller than those in BM were observed as depicted in Figure 5(d) and 6(b).

The SEM analysis of transition zone which is composed of TMAZ and HAZ is depicted in Figure 5(c). It is noticed from the image that there is a close similarity between the heat affected zone and base metal. The transition zone is restricted to 
TMAZ in FS welded matrix composites as also reported by other researchers [16, 20]. As a result of frictional heat experienced in the HAZ softening behavior of the material occurred in HAZ. In TMAZ due to high thermal cycles stretched and swiveled grain structure has been observed as shown in Figure 5(c). The TMAZ undergone serve plastic deformation due to the generation of huge amount of frictional heat by the rotating action of the tool and shoulder.

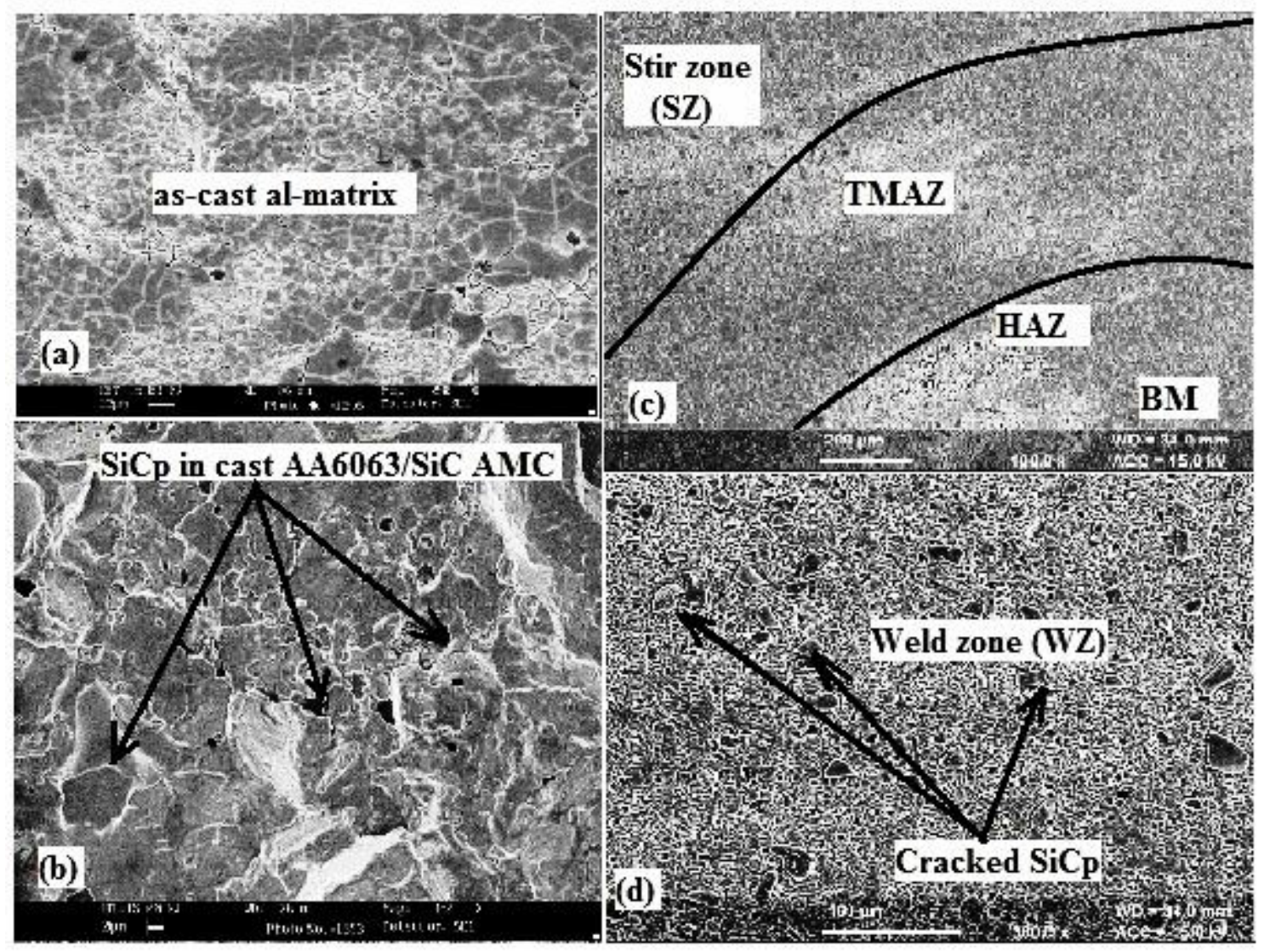

Figure 5. SEM images of: (a) as-cast AA6063 (b) as-cast AA6063/10.5\% SiC AMC (c) transition zone (d) weld zone (WZ).

SEM and OM pictures of WZ as depicted in Figure 5(d) and 6(b) respectively confirmed that in the WZ no segregation of particles has been observed as reported in case of traditional fusion welding processes of AMC. The chances of microporosities associated with the as-cast composite matrix were eliminated following to FSW as noticed in the SEM and OM images in the weld region. A homogeneous distribution of $\mathrm{SiC}$ agents has been noticed in the WZ. The rotating action of the FSW tool induced large strain rate in the plasticized material, as a result of it repositioning of the $\mathrm{SiC}$ agents, occurred in $\mathrm{WZ}$. The aggregates of $\mathrm{SiC}$ agents of as-cast composite matrix scattered in small disc-shaped particles and distributed homogeneously in the WZ. The grain refinement in WZ has been attributed to the dynamic recrystallization occurred during friction stir welding [34]. The EDX analysis of welded al-matrix composite as presented in Figure 7 and Table 2 confirms the presence of $\mathrm{SiC}$ agents in the weld region in notable quantity. The peaks generated during EDX analysis confirmed that the formation of any other compound due to the generation of frictional heat during FSW was denied. The presence of $\mathrm{C}$ and $\mathrm{Si}$ 
elements as shown in the EDX analysis graph in Figure 7 confirms the existence of $\mathrm{SiC}$ particulates in the weld region.
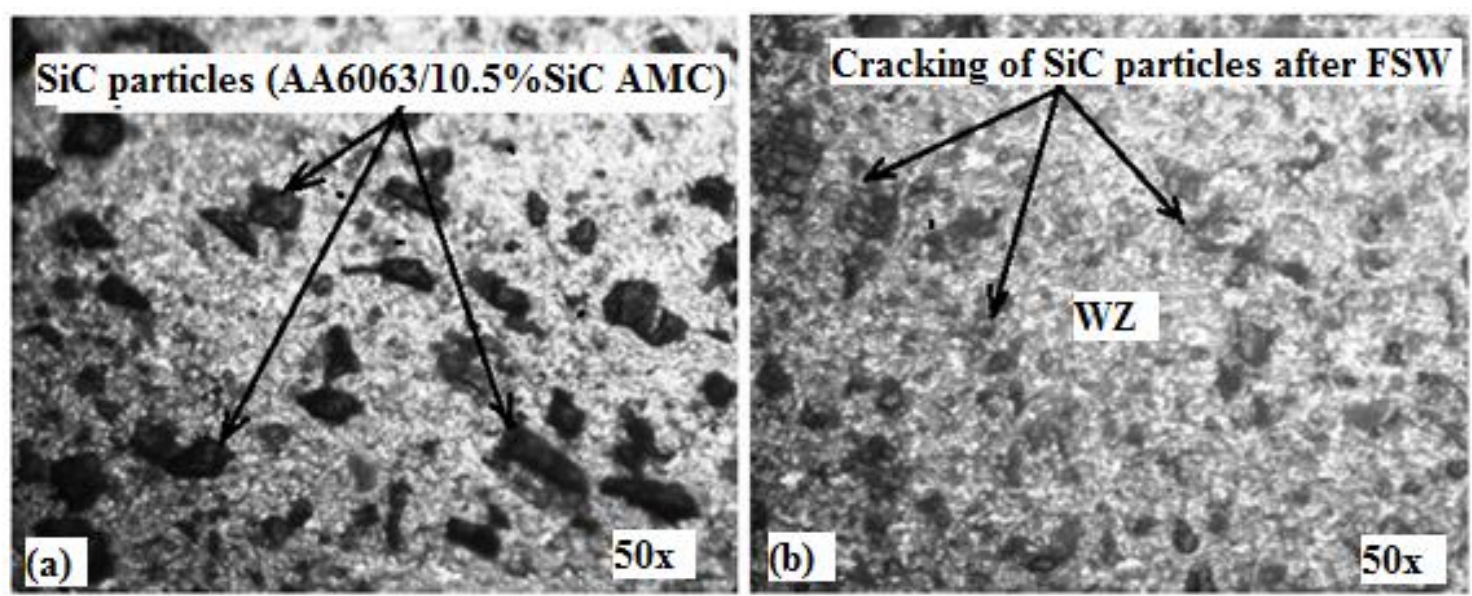

Figure 6. Optical microscopic pictures of: (a) as cast AA6063/10.5\%SiC AMC (b) weld zone (WZ)

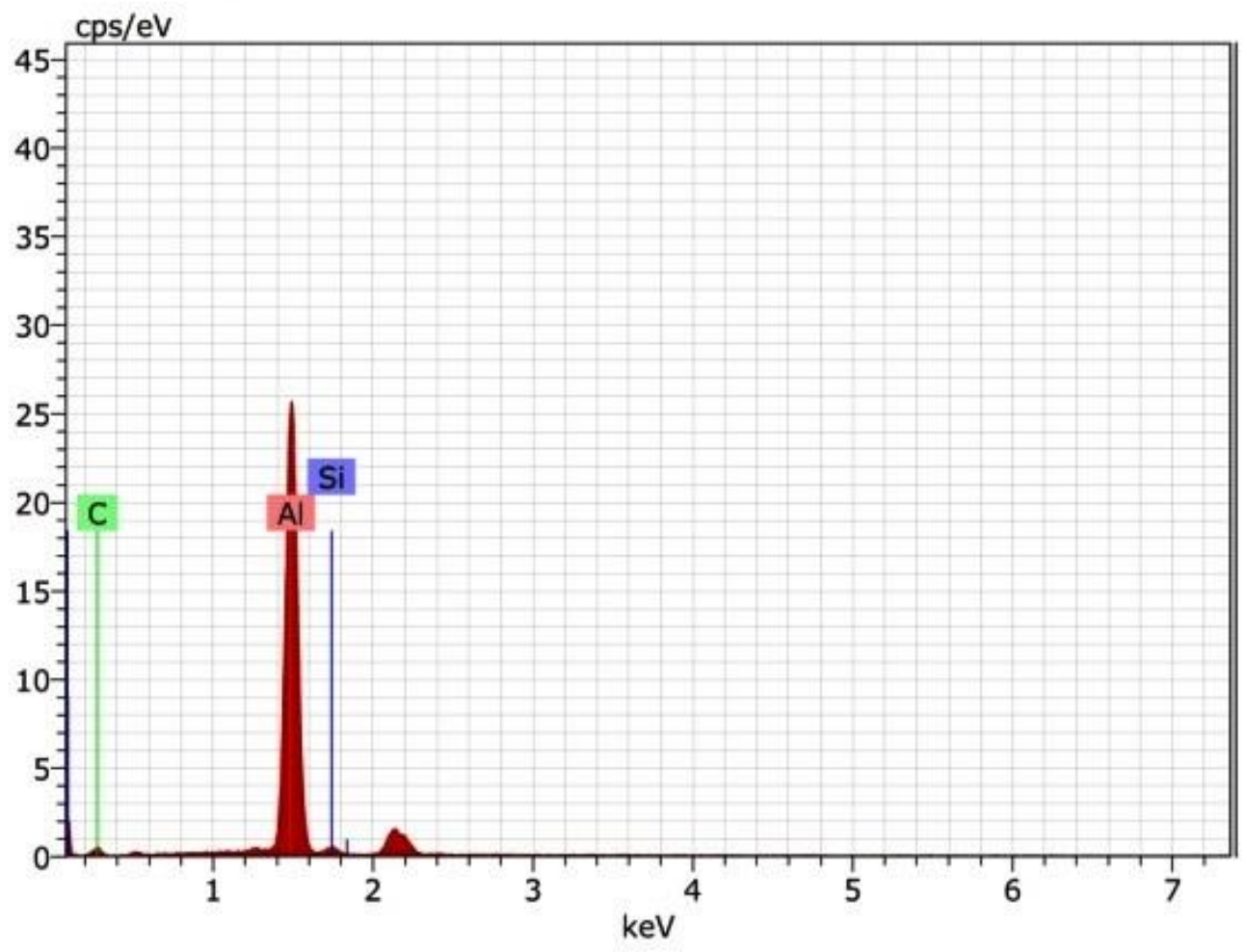

Figure 7. EDX analysis of AA6063/10.5\% SiC AMC of the welded joint

In Table 2, unn. $\mathrm{C}$ [wt. \%] = the unnormalised concentration in weight percent of the element; norm. $\mathrm{C}$ [wt.\%] = the normalized concentration in weight percent of the element; C Atom. [at. \%] the atomic weight percent; (3 Sigma) [wt. \%] = the error in the weight percent concentration at the 3 sigma level. 
Table 2. EDX analysis of AA6063 AMC of the welded joint

\begin{tabular}{cccccc}
\hline Element Series & $\begin{array}{c}\text { unn C } \\
{[\mathbf{w t} \%]}\end{array}$ & $\begin{array}{c}\text { norm C } \\
{[\mathbf{w t} \% \text { ] }}\end{array}$ & $\begin{array}{c}\text { Atom C } \\
\text { [at\%] }\end{array}$ & Error & $\begin{array}{c}\text { \{3 Sigma) } \\
\text { [wt \%] }\end{array}$ \\
\hline Aluminium & 43.51 & 71.27 & 54.22 & 7.52 & 7.52 \\
K-series & & & & & \\
Carbon K-series & 10.11 & 26.21 & 43.91 & 9.17 & 9.17 \\
Silicon K-series & 1.09 & 2.52 & 2.17 & 0.41 & 0.41 \\
\hline Total: & 54.71 & 100 & 100 & & \\
\hline
\end{tabular}

\section{Microhardness examination of the welded joint}

In Figure 8 the microhardness behavior across the weld-section is shown. The weld nugget regions show the higher value of hardness due to the existence of finer $\mathrm{SiC}$ particulates as well as grain refinement of the Al-matrix. Throughout the friction stir welding operation, the stir region is exposed to intense plastic deformation and flow of viscous material in plastic state around tool pin takes place due to stirring action of tool [35]. The generation of heat due to friction throughout the FSW operation is responsible for grain refinement. The stirring action of the tool pin wears the surface of SiC agents and reduction in the size of $\mathrm{SiC}$ agents occurs. The existence of such numerous fragmented small and rounded up $\mathrm{SiC}$ agents with refinement in grain size of Al-matrix remarkably enhanced the mechanical characteristics of the weldments. Hardening of the composite matrix following to FSW also significantly increased the hardness in the WZ [21]. A slight decrease in microhardness value in the TMAZ on both sides of the weld section (i.e. advancing and retreating sides) adjacent to the WZ was noticed. The decrease in hardness in this region is ascribed to the second phase particle dissolution and coarsening prompted by thermo-mechanical conditions. It is observed that the HAZ adjacent to TMAZ on the advancing and retreating side found a gradual decrease in hardness value as compared to the TMAZ. This may be ascribed to the annealing process that takes place in the HAZ [36].

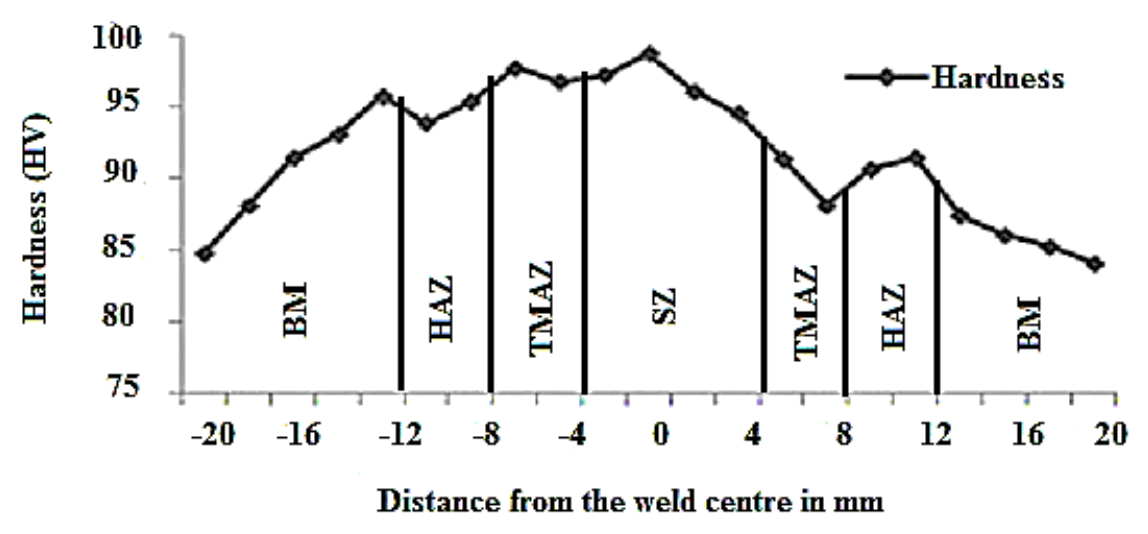

Figure 8. Microhardness across the welded joint AA6063/SiC AMC.

\section{Tensile behaviour of the welded joint}

In Figure 9 the tensile behavior of as-cast AA6063, as-cast AA6063 composite matrix and as welded AA6063/10.5\% SiC AMC joints is depicted. A sharp increase in the 
UTS of the as-welded AMC joint (169MPa) has been observed as compared to the cast al-matrix alloy (132Mpa). The tensile strength of the welded joint has been increased remarkably by the reinforcement of $\mathrm{SiC}$ agents in the Al-matrix alloy. An increase in the dislocation density was observed because of the difference in the thermal expansion coefficient between $\mathrm{SiC}$ reinforcing agents and the aluminum matrix alloy.

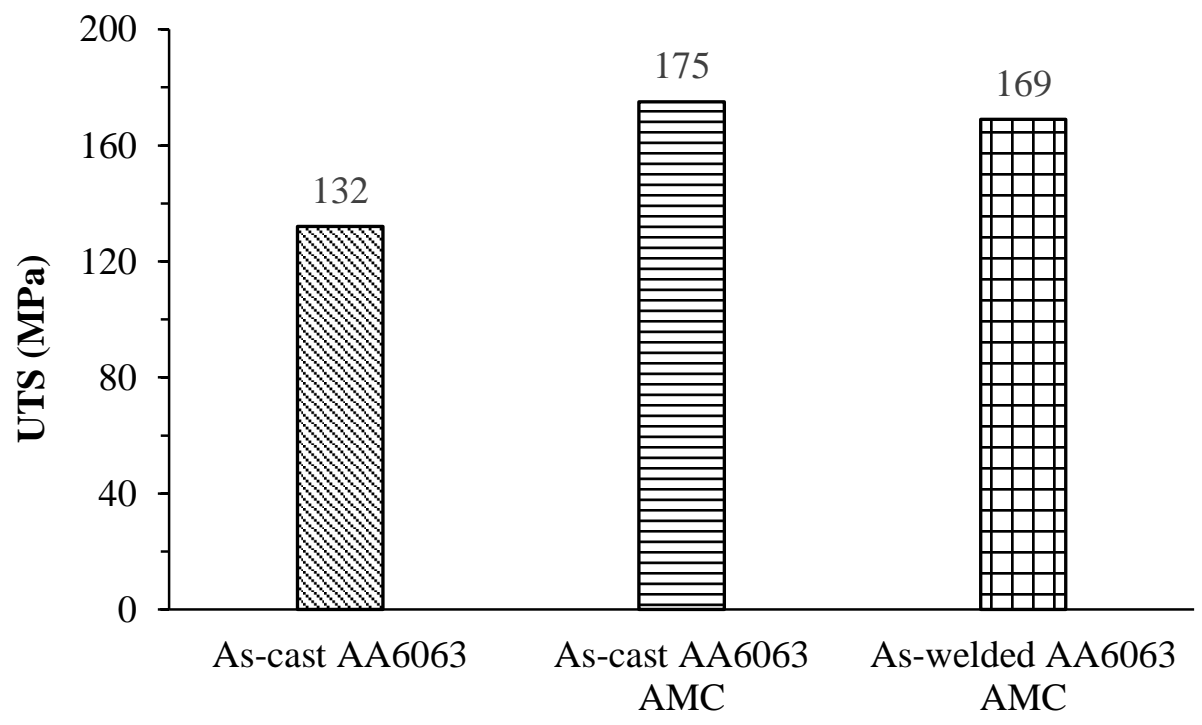

Figure 9. UTS behavior of as-cast AA6063, as-cast AA6063 AMC and aswelded AA6063 AMC

The UTS of the AMC joint (169MPa) was observed very near to the UTS of cast composite matrix (175MPa). A joint efficiency of $96.57 \%$ was recorded for AMC welded joint. At higher tool rotational speed of $124 \mathrm{~mm} / \mathrm{min}$ due to the high heat generation, the plastic flow of material per unit time in the weld zone is increased and reduced the strength of the joint. High rotational rates enabled the whirling away of $\mathrm{SiC}$ particles from the weld zone. Severe clustering of such particles led to the lowering of the tensile strength in the welded AMC joint as compared to the strength of cast composite matrix [37]. The fracture of the FSW weldments occurred near the TMAZ region. An appropriate array of FS welding variables and flaw-free weld section has been assigned to such a high joint efficiency. The combined effect of appropriate welding variables produced sufficient frictional heat, optimal stirring action and carrying of stirred plasticized material. A drop in elongation (\%) of the FS welded joint has been noticed as shown in Figure 10 due to the disintegration of $\mathrm{SiC}$ reinforcing agents and development of fine grains structure in the WZ following to FSW. 


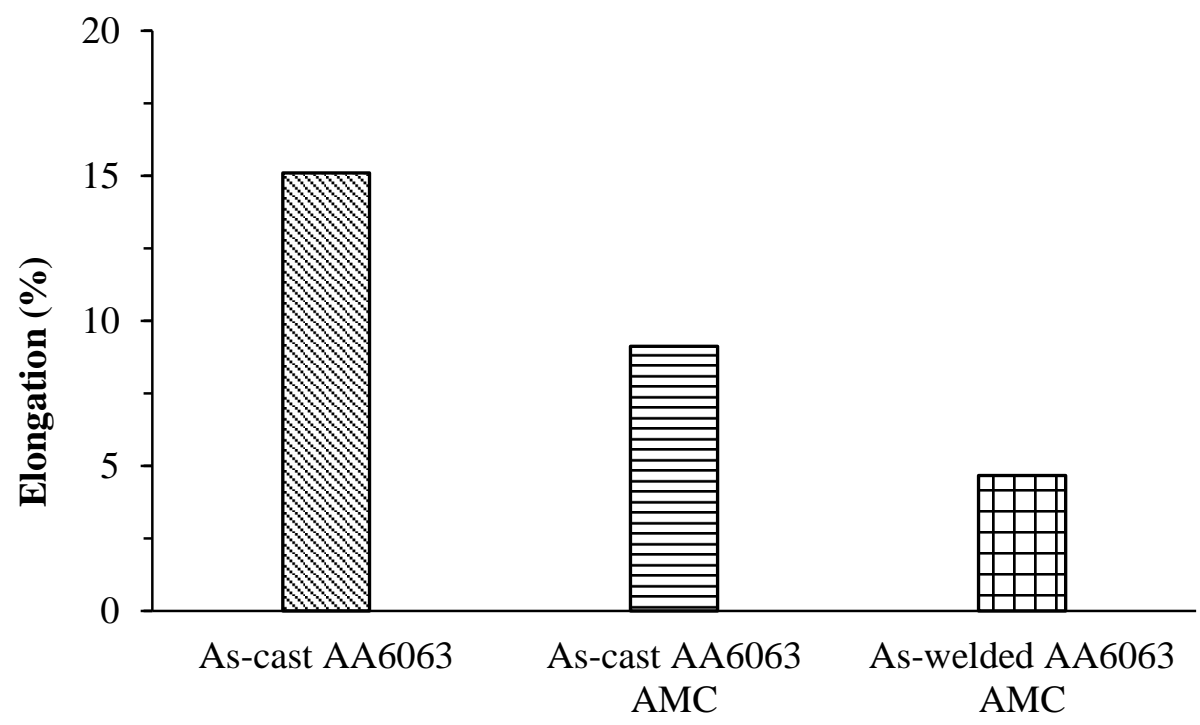

Figure 10. Elongation (\%) behavior of as cast AA6063, as-cast AA6063 AMC and as-welded AA6063 AMC

\section{CONCLUSIONS}

In the present work the fabricated composite plates of AA6063/10.5 wt. \% SiC having $6 \mathrm{~mm}$ thickness were friction stir welded successfully. High strength joint having joint efficiency of more than $95 \%$ has been fabricated using FSW. The UTS of the welded joint was decreased by $3.42 \%$ as compared to the UTS of the base composite matrix because of high heat generation at higher tool rotational rate. The dynamic recrystallization due to FSW in the WZ has an advantageous impact on the uniform dispersal of SiC particles and disintegration of $\mathrm{SiC}$ particle clusters occurred in the stir zone due to the rotating action of the tool. In the weld zone grain size of aluminum matrix has been refined substantially. In the weld region, the coarse grain structure of the al-matrix continuously refined into equiaxed fine grain structure during FSW operation. The fine grain structure in the weld region resulted in high hardness value of the matrix composite in comparison of the base metal composite matrix. The hardening phenomenon observed by the composite matrix following to FSW significantly increased the hardness in the WZ. The decrease in hardness value in TMAZ is ascribed to the second phase particle dissolution and coarsening prompted by thermo-mechanical conditions. The microporosities associated with the as-cast composite matrix were eliminated following to FSW. The dynamic recrystallization in the nugget zone resulted in a higher dislocation density which is responsible for such a high joint efficiency. A drop in elongation (\%) of the FS welded joint was noticed due to the disintegration of $\mathrm{SiC}$ reinforcing agents and development of fine grains structure in the $\mathrm{WZ}$ following to FSW.

\section{ACKNOWLEDGEMENTS}

The experimental and testing work was performed in the Mechanical Engineering Department, NITKKR. 


\section{REFERENCES:}

[1] Maleque MA, Radhi M, Rahman MM. Wear study of Mg-SiCp reinforcement aluminium metal matrix composite. Journal of Mechanical Engineering and Sciences. 2016; 10: 1758-64.

[2] Khan MM, Dixit G. Erosive wear response of SiCp reinforced aluminium based metal matrix composite: Effects of test environments. Journal of Mechanical Engineering and Sciences. 2017; 14: 2401-14.

[3] Kaushik Narinder, Singhaal, Sandeep. Mechanical and Metallurgical Examinations of Stir Cast Aluminum Matrix Composites: A Review Study. International Journal of Engineering and Technology. 2017; 9: 3203-3217.

[4] Sajjadi SA, Ezatpour HR, Parizi MT. Comparison of microstructure and mechanical properties of A356 aluminum alloy/A12O3 composites fabricated by stir and compo-casting processes. Materials \& Design. 2012; 34:106-11.

[5] Kaushik N, Singhal S. Examination of Wear Properties in Dry-Sliding States of SIC Strengthened Al-Alloy Metal Matrix Composites by Using Taguchi Optimization Approach. International Journal of Applied Engineering Research. 2017; 12(20): 9708-9716.

[6] Dinaharan I, Murugan N. Optimization of friction stir welding process to maximize tensile strength of AA6061/ZrB2 in situ composite butt joints. Metals and Materials International, 2012; 18:135-42.

[7] Prater T. Solid-state joining of metal matrix composites: a survey of challenges and potential solutions. Materials and Manufacturing Processes. 2011; 26:63648.

[8] Storjohann D, Barabash OM, Babu SS, David SA, Sklad PS, Bloom EE. Fusion and friction stir welding of aluminum-metal-matrix composites. Metall Mater Trans A. 2005; 36:3237-47

[9] Guo J, Gougeon P, Chen XG. Study on laser welding of AA1100-16 vol.\% B4C metal-matrix composites. Composites Part B. 2012; 43:2400-8.

[10] Xi-he W, Ji-tai N, Kang GS, Le-jun W, Feng CD. Investigation on TIG welding of SiCp-reinforced aluminum-matrix composite using mixed shielding gas and Al-Si filler. Material Science and Engineering: A. 2009; 499:106-10.

[11] Wang SG, Ji XH, Zhao XQ, Dong NN. Interfacial characteristics of electron beam welding joints of SiCp/Al composites. Material Science and Technology. 2011; 27:60-64.

[12] Cam G. Friction stir welded structural materials: beyond Al-alloys. International Materials Reviews. 2011; 56:1-48.

[13] Threadgill PL, Leonard AJ, Shercliff HR, Withers PJ. Friction stir welding of aluminium alloys. International Materials Reviews. 2009; 54:49-93.

[14] Chen XG, Da Silva M, Gougeon P, St-Georges L. Microstructure and mechanical properties of friction stir welded AA6063-B4C metal matrix composites. Material Science and Engineering: A. 2009; 518:174-84.

[15] Vijay SJ, Murugan N. Influence of tool pin profile on the metallurgical and mechanical properties of friction stir welded Al-10 wt.\% TiB2 metal matrix composite. Materials \& Design. 2010; 31:3585-9.

[16] Nami H, Adgi H, Sharifitabar M, Shamabadi H. Microstructure and mechanical properties of friction stir welded $\mathrm{Al} / \mathrm{Mg} 2 \mathrm{Si}$ metal matrix cast composite. Materials \& Design. 2010; 32:976-83. 
[17] Gopalakrishnan S, Murugan N. Prediction of tensile strength of friction stir welded aluminum matrix TiCp particulate reinforced composite. Materials \& Design. 2011; 32:462-7.

[18] Guo J, Amira S, Gougeon P, Chen XG. Effect of the surface preparation techniques on the EBSD analysis of a friction stir welded AA1100-B4C metal matrix composite. Materials Characterization. 2011; 62:865-77.

[19] Bozkurt Y, Uzun H, Salman S. Microstructure and mechanical properties of friction stir welded particulate reinforced AA2124/SiC/25p-T4 composite. Journal of Composite Materials. 2011; 45:2237-45.

[20] Dinaharan I, Murugan N. Effect of friction stir welding on microstructure, mechanical and wear properties of AA6061/ZrB2 in situ cast composites. Material Science and Engineering: A. 2012; 543:257-66.

[21] Guo J, Gougeon P, Chen XG. Characterisation of welded joints produced by FSW in AA 1100-B4C metal matrix composites. Science and Technology of Welding and Joining. 2012; 17:85-91.

[22] Periyasamy P, Mohan B, Balasubramanian V. Effect of heat input on mechanical and metallurgical properties of friction stir welded AA6061-10\% SiCp MMCs. Journal of Materials Engineering and Performance. 2012; 21:2417-28.

[23] Wang D, Xiao BL, Wang QZ, Ma ZY. Friction stir welding of SiCp/2009Al composite plate. Materials and Design. 2013; 47:243-7.

[24] Kalaiselvan K, Dinaharan I, Murugan, N. Characterization of friction stir welded boron carbide particulate reinforced AA6061 aluminum alloy stir cast composite. Materials \& Design. 2014; 55:176-182.

[25] Hasan MM., Ishak M, Rejab MRM. A simplified design of clamping system and fixtures for friction stir welding of aluminium alloys. Journal of Mechanical Engineering and Sciences. 2015; 9:1628-1639.

[26] Vijay SJ, Murugan N. Influence of tool pin profile on the metallurgical and mechanical properties of friction stir welded Al-10wt.\% TiB 2 metal matrix composite. Materials \& Design. 2010; 31(7): 3585-3589.

[27] Wang D, Xiao BL, Wang QZ, Ma ZY. Evolution of the microstructure and strength in the nugget zone of friction stir welded $\mathrm{SiCp} / \mathrm{Al}-\mathrm{Cu}-\mathrm{Mg}$ composite. Journal of Materials Science \& Technology. 2014; 30(1): 54-60.

[28] Bahrami M, Helmi N, Dehghani K, Givi MKB. Exploring the effects of SiC reinforcement incorporation on mechanical properties of friction stir welded 7075 aluminum alloy: fatigue life, impact energy, tensile strength. Materials Science and Engineering: A. 2014; 595: 173-178.

[29] Minak G, Ceschini L, Boromei I, Ponte M. Fatigue properties of friction stir welded particulate reinforced aluminium matrix composites. nternational Journal of Fatigue. 2009; 32:218-26.

[30] Prado RA, Murr LE, Shindo DJ, Soto KF. Tool wear in the friction stir welding of aluminium alloy $6061+20 \%$ Al2O3: a preliminary study. Scripta Materialia. 2001; 45(1):75-80

[31] Brinkmann S, Strombeck AV, Schilling C, Dos Santos JF, Lohwasser D, Kocak M. Mechanical and toughness properties of robotic FSW repair welds in 6061-T6 aluminium alloys. GKSS Forschungszentrum Geesthacht Gmbh-Publications-E. 2000; 1(41), All-All.

[32] Grant GJ, Herling DR, Davies RW. Friction stir welding and processing of aluminium metal matrix composites. In: Proceedings. TMS fall meet. USA. 2001: 177-89. 
[33] Baxter SC, Reynolds AP. Characterisation of reinforcing particle size distribution in a friction stir welded Al-SiC extrusion. In: Proceedings ann. TMS meet. New Orleans, USA. 2001; 284-93.

[34] Kumar A, Mahapatra MM, Jha PK, Mandal NR, Devuri V. Influence of tool geometries and process variables on friction stir butt welding of $\mathrm{Al}-4.5 \% \mathrm{Cu} / \mathrm{TiC}$ in situ metal matrix composites. Materials \& Design. 2014; 59:406-414.

[35] Karthikeyan L, Senthilkumar VS, Padmanabhan KA. On the role of process variables in the friction stir processing of cast aluminum A319 alloy. Materials \& Design. 2010; 31.2: 761-771.

[36] Lima EBF, et al. Dependence of the microstructure, residual stresses and texture of AA 6013 friction stir welds on the welding process. Zeitschrift für Metallkunde. 2003; 94.8: 908-915.

[37] Azimzadega T, Serajzadeh S. An investigation into microstructures and mechanical properties of AA7075-T6 during friction stir welding at relatively high rotational speeds. Journal of materials engineering and performance. 2010; 19.9: 1256-1263. 